\title{
3 Social distancing in the context of COVID-19 in Zimbabwe
}

\author{
Perspectives from Ndau religious \\ indigenous knowledge systems
}

Tenson Muyambo

\section{Introduction and background}

The coronavirus that causes the COVID-19 pandemic has affected all spheres of human life. Jaja et al. (2020:1077) admit that "The 2019 novel coronavirus $(2019-\mathrm{nCoV})$ has altered the way we live, interact and socialize". The pandemic was first discovered in the town of Wuhan in China in December 2019 and declared a public health concern by the World Health Organization (WHO) on 11 March 2020. At the time of writing this chapter, it had spread to the whole world, with Italy, Spain, United States, United Kingdom and China being the most affected statistically. In Africa, South Africa has the highest number of people affected followed by Algeria and Egypt. Zimbabwe had recorded 18 cases and three deaths as of 14 April 2020 as reported by the Ministry of Health and Child Care (MoHCC) (MoHCC 2020a).

In response to the fast spread of the coronavirus and the concomitant death trail in neighbouring South Africa, Zimbabwe promulgated the Statutory Instrument 83 of 2020: Public Health (COVID-19 Prevention, Containment and Treatment), which effectively closed all public and private institutions and instituted nationwide travel restrictions except for essential service providers (MoHCC 2020b). While at home, communities were encouraged to quarantine, stay indoors, constantly wash hands with soap on clean running water, avoid touching the face, use face masks, face shields and practice social distancing whenever outside the home (MoHCC 2020c, $2020 d)$. The Statutory Instrument 83 of 2020 provided that those diagnosed and suspected of having COVID-19 should be quarantined at home and in health institutions to contain the virus. In quarantine centres, COVID-19 patients received a combination of drugs, often used to treat influenza and severe respiratory illnesses (WHO 2020). In extreme cases, seriously ill patients ended up in Intensive Care Unit, with ventilators to assist in their breathing (MoHCC 2020d). All these measures were/are meant to be the safety nets against the pandemic.

In this chapter, I focus on social distancing as one of the many containment measures introduced by the Zimbabwean government. I conceptualise social distancing, analyse its efficacy and establish whether it is a new 
strategy or not among rural communities of south-eastern Zimbabwe. To do this, I identify the problem statement, give the theoretical lens that undergirds the chapter, briefly discuss social distancing or physical distancing, present the study's findings and sum up the chapter by way of a conclusion and recommendations.

\section{Statement of the problem}

Admittedly, COVID-19 took the world by surprise and was declared a world health pandemic. Its declaration must be understood in the context that previously there were pandemics of either a similar nature or of more profound magnitude; yet the level of shock and pandemonium shown by governments was one of hopelessness, to say the least. While WHO came up with laudable recommendations such as social distancing as prevention and control measures, governments implemented it in an ad hoc manner without recourse to how humanity dealt with pandemics of similar nature that befell them in the past and how local communities in their unique circumstances responded to such pandemics. WHO guidelines were and are still being implemented under the "one size-fits-all approach" without taking recognition that contexts ravaged by COVID-19 are varied and different. Such an omission, coupled with lack of community-based COVID-19 education and deep-seated principles of ubuntu may account for the lack of complete compliance to social distancing in Zimbabwe.

\section{Theoretical framework}

The chapter is underpinned by the Sankofa perspective. The Sankofa perspective is derived from an Akan story in Ghana of a mythical bird that moves forward while its head is turned backward toward the golden egg on its back (Slater 2019). The golden egg is symbolic of the treasure of historical wisdom. Loosely translated, the Sankofa simply means "Go back and get it/ Go back and take it" (Slater 2019:2). In other words, the perspective refers to the idea that it is not a taboo to go back and take that which is at risk of being left out yet is essential for survival. It is an approach similar to Cabral's Return to the source (1973) when confronted by new challenges.

The use of this Sankofa lens in this chapter is a clarion call for Africans, Zimbabweans in particular, to rediscover and reclaim historical wisdom to address contemporary problems and challenges. With the advent of COVID-19, the Sankofa perspective is urging Africans to retrace their footsteps into the past in order to understand the present holistically and chart the way forward. Put differently, the Sankofa perspective is of the view that while Africans (though it can be applied anywhere in the world for there is no human race without its historical wisdom) embrace WHO recommendations to curb the spread of COVID-19, such as social distancing, they need to equally look back into the past and rediscover how the past generations dealt with pandemics 
of a similar nature. According to Slater (2019), the Sankofa is interpreted and re-interpreted in several different ways. For the Akan people, Sankofa symbolises Africa's search for knowledge based on critical reasoning, as well as intelligent and patient investigation of the past. This thinking inspired the considerations of this chapter whose thesis is that as humanity searches for measures to curb the spread of COVID-19, it needs to go back to the past and take lessons learnt from past pandemics and epidemics and utilise them to complement and reinforce WHO recommendations for effective prevention and control of the highly infectious COVID-19. Social distancing, as one of such measures, must not be divorced from the religious indigenous knowledge systems of the communities it is meant to serve and save.

\section{Social distancing: a bird's eye view}

Since it is agreed that the coronavirus pandemic does not move but is moved from one locality to another by human beings, social distancing, which "is a method to minimize crowd interactions and prevent the spread of disease within groups of people" (Aslam 2020), is viewed as reducing the rate at which infection takes place. This is a common practice which has been carried out over generations. During the 1918 influenza pandemic, 50-100 million deaths were reported worldwide. Although social distancing was not implemented back in 1918, majority of the population took reactive social distancing measures that made it possible to escape the disease outbreak (Aslam 2020). This behavioural practice followed by several millions led to the pandemic limiting the damage after World War 1 in several European countries. With this in mind, many governments, at the advice and direction of WHO, put in place social distancing or rather physical distance into place. This ranges from one metre to two metres. This recommended distance is believed to curb the transmission of the coronavirus from one person, who could be infected, to another.

Social distancing practices allow individuals to maintain distances from each other for a period of time to ensure the spread of the disease is minimized (Aslam 2020). This would reduce the basic reproduction number (R0) of the virus which would minimize the disease spread (Aslam 2020). A study carried out by Prem et al. (2020) identified that if social distancing practices were carried out properly, an estimate of $92 \%$ of cases would be lowered by the end of 2020. An individual affected with COVID-19 has the ability to spread it to 2-3 people which will go on until they are distanced from each other. There are two common practices followed using social distancing; one of them is social distancing and maintaining a distance of nearly one metre when in public and the other being staying indoors at home. This practice has been successful in the past and in the present as well where Wuhan was able to flatten the disease spread by following these practices.

Reluga (2010:1) argues that social distancing is a zero-cost method that is entirely dependent on behavioural patterns of individuals where most of 
them do not abide by the rules put out in the country. If social distancing methods are ignored the effect could last on for the upcoming generations as the COVID-19 virus will be able to develop different strains where till to date eight different strains of the virus has been discovered by scientists (https://www.news- medical.net/news/20200331/Eight- strains-ofcoronavirus-afflicting-the- world.aspx).

Given the above benefits that accrue due to social distancing, why do most people (globally) resist the practice of social distancing? This question is fundamental when we look at Southern African countries where the people are not only 'notoriously religious' but whose economies, which are largely informal, are shrunk, where people eke a living through vending and other associated businesses. It is also essential to argue that social distancing has come camouflaged by WHO as a new strategy yet Africans in general and Zimbabweans in particular had used and still use social distance when confronted by eventualities beyond their comprehension.

\section{Methodology}

The study adopted a qualitative approach with descriptive study, desk research (Travis 2016), and document analysis (Bowen 2009). Primary data were gathered using face-to-face interviews with ten traditional leaders (five males and five females), five academics (three females and two males), and ten ward councillors of two constituencies in Chipinge district. These purposively selected face-to-face interviewees were opinion leaders in their communities and gathering their views was essential for this study. Since this study was conducted during the lockdown imposed on Zimbabwe as a preventive and control measure, COVID-19 control measures were observed during all the face-to-face interviews. The researcher and the interviewees wore face masks (most of whom were improvisations of home-made masks) and observed social/physical distancing of a least one metre. With a few exceptions where the researcher's hand sanitiser was used for sanitising the hands, hand washing was done using ashes and clean running water before and after the interviews to mitigate any possible infections from the COVID-19. The interviewees' consent was obtained by having them either sign a consent form (for those who could write) or verbally consent (for those who could not write) to ensure that they willingly engaged in the study without coercion. To protect the privacy of the study participants, pseudo identification was utilised to treat all personal information of study participants in anonymity. The study also relied on observations of people's behaviour as they interacted with each other with the intent to take note of the people's uptake (or lack of it) of social distancing as a prevention and control measure against COVID-19.

The gathered data (both primary and secondary) were thoroughly analysed thematically based on the research questions for the study. After the transcription of the interviews, they were verified and validated through member checking with ten selected study participants. 


\section{Results}

Having conducted the study, data were analysed and culminated in the following thematic areas:

\section{Social distancing as "old wine in new wine skins"}

To check whether social distancing as a containment measure against the spread of the COVID-19 pandemic was really a new measure among the indigenous Ndau people of south-eastern Zimbabwe, the following findings were revealed by the participants. Twenty $(80 \%)$ of the participants indicated that social distancing was not new to them. The elderly and traditional leaders were quite conversant with the need to keep a distance from someone who has a contagious disease. They cited the following as some of the ailments that they had to contend with in the past.

\section{Maperembudzi (leprosy)}

Just like the biblical perception of leprosy (Leviticus 13) most Shona people in general, the Ndau of south-eastern Zimbabwe in particular, kept their distance from a person who had leprosy (maperembudzi). Views on how a leprosy patient was handled were summarised by one traditional leader (TL1) who submitted thus:

Before the advent of clinics and hospitals, we used to have frequent cases of maperembudzi in our communities. This was a disease which could be transmitted very easily from one person to another. As a prevention measure we would isolate the infected person. A hut could be built some distance from the homestead and this person could be nursed from there. We made sure that the person does not come in contact with anyone for some reasonable period. Even conjugal rights were denied of that patient. Food was provided to him/her under very strict observances lest the one caring for the patient got infected too.

The above submissions were re-echoed by one ward councillor (WC3), who stated thus:

As we were growing up, our elders used to tell us stories about michhachha (makeshift huts) built at the fringes of the homestead where people with contagious ailments like maperembudzi were kept for the period of the ailment. The person was quarantined and all other people were supposed to keep distance (social/physical distancing) from the infected. While the infected person was quarantined, his/her family members would ensure that s/he gets the family support such as provision of food, bathing and clothing. Those who could come closer to the patient needed to be careful not to get infected too by putting on protective clothing. 
A female culturist academic (A2) who was interviewed also intimated:

From the past people have had pandemics that warranted them to keep a distance from the infected. Although the keeping of distance was not known by 'social distancing' then, it is quite true that pandemics and epidemics of this nature abounded. Given that social/physical distancing has been there not only in the COVID-19 context but during other pandemics/epidemics in the past, building on what the people already know from their past experiences with pandemics or epidemics could increase the uptake of social distancing by locals as one of the containment measures against COVID-19.

\section{Manyembana (chicken pox)}

Research participants understood manyembana (chicken pox) as skin boils (maronda anobuda mvura mumuiri weshe). The participants indicated that in severe circumstances, the disease had disastrous consequences such as crippling the patient, death and was said to be highly infectious. This was summed up by one traditional leader (TL4) who stated thus:

Manyembana is no longer common but was a highly infectious disease that also made the patient to be quarantined. The patient was put in a hut away from the homestead and people would take turns to go and see the patient. Body contact was highly prohibited. The patient's food was placed at the entrance of the hut and the patient would serve himself/ herself. With full knowledge of their conditions, the quarantined patients would accept the treatment from family members. They could not begrudge them for they fully understood that coming in contact with the family members the infection would spread to others. They had to endure for the period until the ailment was completely healed.

The excerpts above are, indeed, illustrative of how the concept of separation/ quarantine was instituted among the Ndau rural communities when an individual was infected by a contagion. The above cited infectious diseases were as contagious as is COVID-19, meaning that measures that were instituted for these diseases can be applied to any infectious disease. Social/physical distancing is, therefore, not new when it comes to COVID-19 discourse.

\section{Biripiri (measles)}

Biripiri (measles) was yet another ailment that called for caution and alertness when it afflicted an individual. Participants were unanimous that biripiri (in Ndau language), was (my use of the past tense is prompted by the fact that with immunisation most of these ailments are on the curb, though instances of them occurring are possible but with less severity as was in the 
past before immunisation), an infectious disease which warranted the infected person to be isolated from others. Most of the participants' views can be summarised by what one traditional leader (TL4) said:

When a person was infected by biripiri one was given accommodation where others could not be in contact with him/her. Ordinarily, biripiri was very common among the young. When a child was infected, s/he was separated from the others. S/he was put in a hut (muchhachha) at the margins of the homestead. During the quarantine period, parents of the child were asked to refrain from sexual intimacy, for doing so would risk the child's life. In fact, biripiri had become a rite of passage for one was supposed to pass through it. If a child grew up into adulthood without having been hit by biripiri, the parents became worried. If one was infected by the ailment and recovered, one's immunity would have been boosted and would not be prone to other attendant ailments.

Additionally, another participant, an elderly ward councillor (WC3) had this to say:

Biripiri is/was an ailment that could also affect the mature people, not only the young. It was a disease that one had to suffer from, especially when still young. When a person passed his/her teens without having been affected by the disease, people were sure that it would one day affect him in adulthood. At adulthood, the ailment could be more severe and would need rituals to be performed such as making confessions, commonly known as kudura in Ndau language. That a person affected by biripiri was quarantined in a hut away from the homestead was accepted at a family level, by everyone; both the patient and the family members were inducted to accept this reality.

\section{Mphezi (scabies)}

This contagious disease was equally indicated to be one of the ailments that need no skin contact lest it spreads that way. One academic (A1) expressed that:

As we were growing up in the villages, we were urged to stay away from friends who would have been infected by scabies, lest we too would get infected. Though it was difficult to separate oneself from an infected friend, we were told frightening stories that would force us not to be close to the affected friend. It did not make sense to us then but am now seeing the logic behind. It was meant to reduce the spread of the disease amongst friends. The affected friend was kept under close supervision by the parents so that s/he did not infect others in the community. This was another form of physical distancing, in my view. 
The above excerpt illustrates that the separation approach was a painful experience. It hurts both the infected and his/her friends by physically marooning them, thereby emotionally make them miss each other. Mantineo (2021:29) sums up the emotional effect of social distancing by admitting that the dominant feelings of it are "sorrow, grief, and loneliness..." Although the net effect of this exclusion was meant to keep the pandemic/epidemic within manageable limits, it was psychologically numbing as evident in the excerpts above. In some cases, social distancing resulted in some stigma and labelling as A2 revealed that being afflicted by the epidemics was scorned at "une maperembudzi", a phrase not readily acceptable to the victim just like it was/is to say “une AIDS' (He/she has AIDS).

\section{The Ndau way of greeting as a safety net against COVID-19}

Apart from the forced social distancing imposed by the cited diseases, the Ndau people, who are the participants of this study, have a unique way of greeting. Among indigenous Ndau people shaking of hands and hugging each other, especially between people of a different sex are not only discouraged but castigated as indecorous behaviour (though such taboos are under siege from globalisation and acculturation). The elderly interviewees' views were summarised by one traditional leader (TL5), a village headman. He had this to say:

We are told that handshaking and hugging are some of the ways through which the virus is spread. As for some of us, who are the real custodians of our culture, handshaking and hugging are not very common because for us there is no respect in doing this. We greet each other with dignity, clapping our hands while sitting down especially when greeting the village head or chief. Reasonable distance is kept between the village head/ chief and the subjects. For instance, sons and daughters-in-law keep a distance when greeting their fathers and mothers-in-law. Although we are witnessing changes in how greeting is done these days, in these contexts of COVID-19, our beliefs and practices reign supreme.

Probed further, the interviewee indicated the kind of greeting that happens between a mother-in-law and her son-in-law. The son-in-law takes a respectful body position clapping hands while the mother-in-law literally sits down clapping hands too, with the two literally not looking at each other face to face. This, according to the interviewee, is a sign of respect and a high demonstration of untu (humaneness, humility, meekness and gratitude). Chances that COVID-19 may be transmitted here are minimal for there is reasonable physical distance between the son-in-law and mother-in-law. The practice, which could be on the verge of extinction in the Fourth Revolution, can become handy if all people in the COVID-19 context treat each other in the manner the Ndau son-in-law and mother-in-law relate to one another. This traditional behavioural practice can be turned into a public health safety net. 


\section{Social distancing and Ubuntu among the Ndau}

On whether social distancing does not violate the principles of $u b u n t u$, one traditional leader (TL3) summarised the interviewees' views as follows:

There is a serious dilemma that we face when we are asked not to be in contact with our dear infected kinspeople. While we are aware of the consequences of the contact, it remains inhuman for us to separate ourselves from the sick. Firstly, it is extremely difficult for the caring person. Secondly, it has serious psychological effects on the patient. One feels rejected or rather discriminated against. Our ubuntu values teach us to care and love the infected. This care and love come in the form of closeness to the patient, talking to him/her, re-assuring her/him that this is just a passing phase. This is what this highly infectious disease thrives on. We are, therefore, left wondering what to do, keep ourselves away and not being infected or be close enough to the infected to be infected too?

The same pessimism was shared by another interviewee who talked about the way funeral proceedings of the victims of the pandemic are carried out. She (A2) had this to say:

We are deeply concerned about the way our departing ones are being buried. We no longer observe burial rites for a person who has died of COVID-19 related complications that include: having the corpse in the house a night before burial, no body bathing, no body reviewing and many other associated funeral rites. A person, in some instances, is laid to rest by health and funeral agents who are not even related, strangers to the deceased. This has serious consequences for the deceased and the deceased's close relatives. This flouts our beliefs and values on death and funeral rites. That sense of communitarianism is no longer there. The 'I am because of others' is seriously challenged.

A female traditional healer, who was part of the key informant interviewees among the traditional leaders, had this to say:

Oooh! To die and your children failing to touch your body is the most painful thing to happen in one's life. This is unacceptable in our culture as Ndau people. I will turn in my grave and definitely punish them for abandoning me. I must die in the hands of my children. My funeral rites must be observed fully.

During fieldwork, I observed that most funerals held in the rural areas compromised a lot on observing WHO and the Ministry of Health and Child Care (MoHCC) guidelines on funerals. Health officials, (who usually are 
members of the bereaved communities), who were supposed to enforce these stipulations, were held back by socio-cultural beliefs and values. As such COVID-19 containment measures like proper face masking, social distancing, handwashing using soap on clean running water and not coming too close to a COVID-19 corpse were relaxed, risking many lives. The health officials found it very difficult, in the rural areas, to coerce members of the communities they were too accustomed to, to abstain from carrying out the funeral rites. Instead, the officials tended to ignore the flouting of the COVID-19 regulations during mourning and burial.

\section{Discussion}

Participants in the interviews were clear that social distancing was not necessarily new but a practice that was there from time immemorial, especially among the Ndau people. They indicated that the epidemics and pandemics were dealt with by putting in place the socio-cultural beliefs and practices (which I can refer to the Ndau people's indigenous knowledge systems) commensurate with the people's socio-cultural milieu. This puts traditional communities on a vantage position when it comes to the COVID-19 pandemic containment measures. Unfortunately, this vantage position is not utilised for the benefit of the communities confronted by what OkyereManu (2021) identified as 'the lion attacking the village'. Ndhlovu-Gatsheni is instructive when he argues thus:

The ironic part is that even among Africans-who have a long history and experience of grappling with epidemics and pandemics, largely because of the negative impact of modern global power dynamics, which invented and reproduced the Global South as the geography of povertythere is reluctance to tap into this history, experience, and knowledge about responding to the COVID-19 pandemic.

$(2020: 370)$

This argument emanates from the realisation that there is a tendency to look for answers to problems from outside the context of the problem. For instance, when the COVID-19 pandemic hit the world the most logical thing was to look for contextual responses. Rather, what happened is that WHO came up with a one-size-fits-all approach where the Global North and the Global South were, all of a sudden and surprisingly, symmetric. The assumption made was that all nations were tabula rasa when it comes to the pandemic. Little did the Global North know, that pandemics of this nature were not necessarily new to the Global South, as Ndhlovu-Gatsheni (2020:372) points out that "the COVID-19 has plunged the world into an unfamiliar territory though it is not so unfamiliar to the Global South, where a majority of people live in what Fanon (1968) termed the 'zone of nonbeing". Admittedly, there is need for a global solution to a global problem 
but we need not lose sight of the heterogeneity that characterises continents and countries. Zeleza (2020) cautions that we need an African solution to a global problem.

Given the foregoing, the thesis I am advancing is that instead of coming up with a one- size-fits-all approach to the COVID-19 pandemic, WHO and ministries of health in various nations were supposed to prioritise flattening the curve taking into cognisance countries potentialities and capabilities. For example, when Madagascar tried to institute its local expertise to curb the spread of the virus, it received unwarranted criticisms from WHO and its allies. This inferiorisation and othering of other people's knowledge systems is tantamount to epistemic violence and genocide. As participants indicated, ailments such as measles, leprosy, and chicken pox warranted physical distancing. Instead of bringing social distancing as a new measure, WHO and its agents should have advocated for the utilisation of the local people's past experiences with pandemics/epidemics of a similar nature and use the experiences as building blocks towards finding solutions to the COVID-19 challenge. This is what developmental scholars believe in when they talk of the B4 model (Building the Build Back Better model) (Nhamo \& Chikodzi 2021). The call is for the Global North to realise that circumstances differ. An anonymous writer says "If New York never sleeps because the lights are always on and there's always somewhere to be, Lagos never sleeps because there's no power and it's much too hot indoors", which brings us the stark reality that while other communities are luxurious and spacious, others, even if they want to, simply do not have the space to be that luxurious. Taking their existential circumstances when dealing with challenges is fundamental.

It has also been evident from the participants that while social distancing is recommended at funerals, it is not just practical in some socio-cultural contexts. The psychological pain that the bereaved have to go through when the loved departed one is never given the full burial rites as per custom is just unbearable. The idea of a victim of COVID-19 coming straight from a funeral parlour to the grave where trained health officials take over the proceedings is hard to accept. This is why COVID-19 funerals are very difficult to manage in the rural communities as observed during fieldwork. Deopa and Fortunato (2020) concur when they argue that while the health measures enacted have been, on the average homogenous across all cultures, compliance to these rules varied widely within the local context. The fear to anger the spiritual world forced some people to flout COVID-19 funeral stipulations. Imaging a mother dying not in her children's hands (literally) is treated as an anathema that may result in kutanda botso (appeasing the avenging mother's spirit). People find themselves in a cul de sac, either to follow health officials' guidelines and anger their ancestors or to flout the funeral regulations. Okyere-Manu (2021) poignantly says that this raises an ethical dilemma for us as Africans. We are to either choose life affirming practices or ignore the public health call. 
An anonymous writer in the Correspondent of 27 March 2020 submits that social distancing will not work for Africans. For the anonymous writer, social distancing is not just alien to Africans, it is impossible for social and economic reasons too. We have witnessed how families' livelihoods have been affected by national lockdowns in the Third World countries. While social distancing is the catchword for $\mathrm{WHO}, \mathrm{WHO}$ is forgetting (consciously or unconsciously) that there are many parts of the world where this single solution is contextually inadequate or even dangerous. I call to mind here fundamental questions that Okyere-Manu (2021) raises. She queries:

Some of these choices are relatively rudimentary - choosing not to have an evening event with friends to share meat, music and conversation is simple enough. But what happens to that same choice when a baby is born? A young couple gets married? A young intelligent member of our neighbourhood graduates?

While the above excerpt may be looked at casually, the cited events call for the serious need to demonstrate ubuntu. Okyere-Manu points to the serious dilemma most people find in social distancing no wonder people flout it as it contradicts the people's sense of ubuntu. Sambala et al. (2019) attribute the rise of ethical problems to disproportionate interventions and intrusive public health measures. According to Sambala et al. (2019), interconnections, interdependence and interrelationships are the pillars of $u b u n t u$. Social distancing defeats interrelationality and sociality. African people have to contend with dictates and teachings from African indigenous religions and the scientific pronouncements made about pandemics. The dichotomous variations between science and religions are at play, and because Africans, who are "notoriously religious" (Mbiti 1969: 1) revere and venerate ancestors, they fear angering their spiritual world. They would rather jeopardize their lives than angering the ancestors. This explains why they continue, against science recommendations, to attend and carry funeral rites that risk their lives in COVID-19 funeral contexts. They choose religion instead of science.

\section{Linking the past, present and the future: lessons from the Sankofa bird}

The foregoing arguments are a culmination of what used to happen, what is happening and what we need to do. Using the Sankofa perspective, I submit that while the behaviour of WHO and health ministries of many governments, particularly in Southern Africa is acceptable, treating countries as homogenous who need a homogenous solution to a global problem stifles rooms for creativity, ingenuity and innovation. Southern African governments must not "cut and paste" (Mocamo 2020: 1) European responses to the COVID-19 pandemic. The clarion call is "let us go back to the past, take that which is useful and blend it with that which is at our disposal for 
sustainable solutions to existential challenges such as the COVID-19 pandemic" (Mocamo 2020: 1). This chapter is by no means a total rejection of modern measures by health experts but a plea for the need to tap from the known into the unknown, from a people's indigenous knowledge into science. Social distancing that used to be there in pandemics and epidemics mentioned by participants needs not to be ignored. I argue that we need to build from the known to the unknown. This has an advantage in that uptake of measures may be increased for a people's socio-cultural milieu would have been taken into consideration in the search for COVID-19 containment measures. In other words, let us learn from the Sankofa bird.

On how the past experiences can be the building blocks on flattening the curve, the creation of community-based task forces headed by traditional leadership to educate the public on the need to balance Western and local interventions to increase the uptake of WHO recommendations is more urgent than ever. This is where traditional chiefs, kraal heads and headmen become handy. These traditional leaders derive respect and trust from their members. This is a competitive advantage in that they are more likely to be hearkened to when they actively participate in COVID-19 containment measures education campaigns. Dziva argues:

As custodians and enforcers of traditional customs and values, endogenous leaders are widely relied on and respected in rural communities such that their encouragements, orders and coercive interventions can positively combat the deadly coronavirus. With the fear for punishment in the form of cursing or being ostracized, ruralites often listen to and abide by traditional leaders' calls and pleas to stay at home, practice personal hygiene and observe social distancing. Based on these cutting edge advantages, chiefs and their decentralized structures can play a key role in community mobilization, raising awareness, dispelling pandemic rumours and myths, vaccine utilization and pushing for compromises where measures are incompatible with local traditions, cultural values and norms.

(2020:509)

Failing to utilize this abundant resource at its disposal, the Zimbabwean government is failing the whole nation. If ever there was a time to seriously harness a people's socio-cultural capital, it is now. Traditional leaders must not only be found convenient during elections but also during health crisis such as COVID-19.

\section{Conclusion}

This chapter has discussed social distancing from a Ndau religious indigenous knowledge systems, where the argument is that there is scope to tap from past experiences. It has concluded that social distancing is a safety 
valve that communities in south-eastern Zimbabwe utilised to reduce the impact of epidemics and pandemics and that it is, therefore, not a new strategy in the context of COVID-19. The containment measure has come in Eurocentric packages, ignoring what local communities used to do in the past. This one-size-fits-all approach has been rejected in this chapter. The chapter has suggested the B4 model where eventualities such as COVID-19 hits, there is need to build on build back better (BBBB) where the thrust is to tap on what communities used in curbing previous epidemics and pandemics and improve where need be. The chapter has also accounted for the lack of compliance when it comes to social distancing during funerals. Principles of ubuntu are not amenable to social distancing, particularly during religious burial rites. This dilemma needs to be untangled by robust education platforms where the locals are educated on the need to deal with COVID-19 in a culturally responsive context. Traditional mechanisms such as traditional leadership's agency must be used in the education of the locals, an education that is not too divorced from the socio-cultural milieu of the locals. Such an education would reduce confrontation and resistance in the fight against COVID-19.

\section{References}

Aslam, F. 2020. COVID-19 and the importance of social distancing. www.preprints. org. Accessed 28 October 2020.

Bowen, G. 2009. Document analysis as a qualitative research method. Qualitative Research Journal, 9(2), 27-40. https://doi.org/10.3316/QRJ0902027.

Cabral, A. 1973. A Return to the Source: Selected Speeches by Amilcar Cabral. New York: NYU Press.

Deopa, N. and Fotunato, P. 2020. Coronagraben: Culture and social distancing in times of COVID-19. UNCTAD Research Paper No. 49. https://unctad.org/system/files/official-document/ser-rp-2020d8_en.pdf. Accessed 10 March 2021.

Dziva, C. 2020. The potential and challenges for traditional leadership in combating the COVID-19 pandemic in rural communities of Zimbabwe. African Journal of Governance and Development, 9(2), 509-523.

Fanon, F. 1968. The Wretched of the Earth. Cambridge: Grove Press.

Jaja, I.F., Umunna, M. and Jaja, C.J.I. 2020. Social distancing: How religion, culture and burial ceremony undermine the effort to curb COVID-29 in South Africa. Emerging Microbes and Infections, 9(1), 1077-1079.

Macamo, E. 2020. The Normality of Risk: African and European Responses to COVID-19.https://www.coronatimes.net/normality-risk-africa-european-responses/ Accessed 8 March 2021.

Mantineo, A. 2021. I have a dream: Restarting, but going where? In Pierluigi Consorti (ed.). Law, Religion and COVID-19 Emergency. Pisa: DiReSoM, 29-34.

Mbiti, J.S. 1969. African Religions and Philosophy. Blantyre: Heinemann.

Ministry of Health and Child Care. 2020a. Coronavirus (COVID-19) Update Statement. 14 April 2020.

Ministry of Health and Child Care. 2020b. Coronavirus (COVID-19) Update: Zimbabwe, 19 June 2020. 
Ministry of Health and Child Care. 2020c. Zimbabwe COVID-19 SitRep: Update: Zimbabwe, 6 September 2020. http://www.mohcc.gov.zw/index.php?option $=$ com_phocadownload $\&$ view $=$ cate gory\&id=15\&Itemid $=742$. Accessed 28 September 2020.

Ministry of Health and Child Care. 2020d. Stay at home \# stay safe \# defeat COVID-19, 8 April 2020. http://www.mohcc.gov.zw/index.php?option=com_content $\&$ view $=$ cat egory\&layout $=$ blog $\& i d=103 \&$ Itemid $=743$. Accessed 28 September 2020.

Ndlovu-Gatsheni, S.J. 2020. Geopolitics of power and knowledge in COVID-19 pandemic: Decolonial reflections on a global crisis. Journal of Developing Societies, 36(4), 366-389.

Nhamo, G. and Chikodzi, D. 2021. Cyclones in Southern Africa Volume 1: Interfacing the catastrophic impact of cyclone Idai with SDGs in Zimbabwe. Switzerland: Springer.

Okyere-Manu, B. 2021. Coronavirus: The Lion is attacking the village. https://beatriceokyere.com/post/coronavirus-the-lion-is-attacking-the-village. Accessed 4 February 2021.

Prem, K., Liu, Y., Russell, T.W., Kucharski, A.J., Eggo, R.M., Davies, N., Flasche, S., Clifford, S., Pearson, C.A., Munday, J.D. and Abbott, S. 2020. The effect of control strategies to reduce social mixing on outcomes of the COVID-19 epidemic in Wuhan, China: A modelling study. The Lancet Public Health, 5(5), e261-e270. Published online 2020 Mar 25. doi: 10.1016/S2468-2667(20)30073-6

Reluga, T.C. 2010. Game theory of social distancing in response to an epidemic. PLoS Computational Biology, 6(5), 1-9.

Sambala, E.Z., Cooper, S. and Manderson, L. 2019. Ubuntu as a framework for ethical decision making in Africa: Responding to epidemics. Ethics and Behavior, $30(1), 1-13$.

Slater, J. 2019. Sankofa-the need to turn back to move forward: Addressing reconstruction challenges that face Africa and South Africa today. Studia Historiae Ecclesiasticae, 45(1), 1-24.

Travis, D. 2016. Desk research: The what, why, and how. User Focus. https://www. userfocus.co.uk.

World Health Organization (WHO). 2020. Coronavirus disease (COVID-19) outbreak situation. https://www.who.int/emergencies/diseases/novel-coronavirus2019?gclid=EAIaIQobChMIv5yAiOfY6wIVpoBQBh2LEwgEEAAYASAAEgLk u_D_BwE. Accessed 10 October 2020.

Zeleza, P.T. 2020. The coronavirus: The political economy of the pathogen. Elephant. 1-23. https://www.theelephant.info/long-reads/2020/03/25/the-coronavirus-thepolitical-economy-of-a-pathogen/ Accessed 5 March 2021. 